\title{
Bacteria That Shove Harder, Move Further
}

\author{
Simulations show that the harder bacteria in a swarm push against one \\ another, the more likely they are to go on long "walks."
}

\section{By Rahul Rao}

S warms of bacteria seem to house miscreants. In such dense clusters, bacteria push and shove against each other like concertgoers in a mosh pit. Statistical physics models predict that individual bacteria shouldn't be able to burst through the crowd and diffuse long distances, yet, bafflingly, some bacteria do exactly that. Now, using simulations, Siddhartha Mukherjee and colleagues at the International Centre for Theoretical Sciences of the Tata Institute of Fundamental Research, India, have come up with a possible cause for this unexpected behavior: The push of the bacteria against one another can, if it is strong enough, change the flow pattern within the colony such that this "super" diffusion can happen [1].

Swarms of bacteria behave like fluids. But experimental studies of bacteria swarms show that some bacteria can superdiffuse. These bacteria go for "Lévy walks," which consist of long straight paths interspersed with sharp turns. Replicating these Lévy walks and finding their cause, however, has, until now, eluded

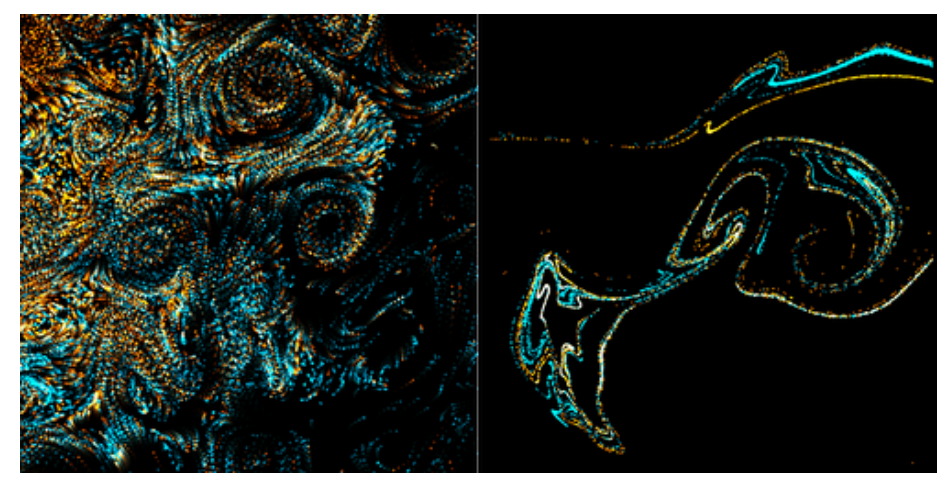

Credit: S. Mukherjee et al. [1] simulations, which previously were unable to reproduce them.

Mukherjee and his colleagues conducted their simulations using a hydrodynamic model to capture the turbulence of the bacteria swarm. They noticed previously unseen turbulent "streaks" form within the bacteria cluster, which they find facilitate Lévy walks. Varying how hard the bacteria pushed against each other, they found that as the swarm became denser and as the bacteria jostled with more zeal, the streaks became longer. The team says that they think bacteria go on Lévy walks to forage efficiently and evade hazards, two things that should help them survive.

Rahul Rao is a freelance science writer based in New York.

\section{REFERENCES}

1. S. Mukherjee et al., "Anomalous diffusion and Lévy walks distinguish active from inertial turbulence," Phys. Rev. Lett. 127, 118001 (2021). 